\title{
Suppurative coxitis due to Salmonella typhimurium in systemic lupus erythematosus
}

\author{
KENZO SHIOTA, FUMIO MIKI, YOSHIHARU KANAYAMA, \\ MASAKAZU KOHNO, AKIKO OHE, KENJI TAKAMATSU, AND \\ TAKATOSHI INOUE
}

From the First Department of Internal Medicine, Osaka City University Medical School, 1-5-7 Asahimachi, Abenoku, Osaka, Japan

SUMMARY A 36-year-old woman with systemic lupus erythematosus (SLE) developed septicaemia and subsequently suppurative coxitis due to Salmonella typhimurium. Although systemic treatment with antibiotics eradicated salmonella from the arterial blood, cup arthroplasty and irrigation of the operative wounds with effective antibiotics were needed for eradication of the organism from the affected joints.

Suppurative bacterial arthritis is an uncommon complication of systemic lupus erythematosus, ${ }^{1}$ and only 1 case of coxitis caused by Salmonella typhimurium has been reported previously as a necropsy finding. ${ }^{2}$ The diagnosis and successful treatment of a patient is reported below.

\section{Case report}

A 36-year-old woman was admitted to Osaka City University Hospital on 31 March 1977 complaining of dull pain in the epigastrium, nausea, vomiting, and diarrhoea. Three years previously she had suffered from episodic fever, finger tip erythema, polyarthralgia, and myalgia, and she was found to have leucopenia and a positive LE cell test, but had not received any special treatment.

On examination, she was pale, her temperature was $36.6^{\circ} \mathrm{C}$, and the blood pressure was $120 / 80$ $\mathrm{mmHg}$. The heart and lungs were normal. On palpation there was diffuse abdominal tenderness but no rigidity. Movement of both upper and lower limbs caused joint and muscular pain. The urine contained $8 \mathrm{mg} / 100 \mathrm{ml}(0.08 \mathrm{~g} / \mathrm{l})$ of protein with normal sediment. Haemoglobin was $11.6 \mathrm{~g} / \mathrm{dl}$. The white cell count was $3.7 \times 10^{9} / \mathrm{l}$, with a normal differential count. The erythrocyte sedimentation rate (Westergren's method) was $72 \mathrm{~mm}$ in 1 hour. Serum values for urea nitrogen, SGOT, SGPT, and

Accepted for publication 25 March 1980 Correspondence to Dr T. Inoue. bilirubin were normal. A test for rheumatoid factor was positive. A serological test for syphilis was negative. Complement was $7 \cdot 1 \mathrm{U}$ (normal, 29 to 45 $\mathrm{CH} 50 \mathrm{U}$ ). An LE cell test was positive, and an Antinuclear test factor was positive. The serum anti-DNA antibody titre was more than $\times 2560$ (normal, less than $\times 40$ ). Electrocardiogram and chest roentgenogram were both normal.

A diagnosis of systemic lupus erythematosus was made, and lupus vasculitis of the gastrointestinal tract was also considered. The patient was treated with $60 \mathrm{mg}$ of prednisolone daily, and her gastrointestinal symptoms quickly subsided. However, on April 28 her temperature rose to $38^{\circ} \mathrm{C}$, diarrhoea recurred, and faecal and arterial blood cultures yielded Salmonella typhimurium. Although treatment with chloramphenicol ( $3 \mathrm{~g}$ per day) eradicated the salmonella from both faeces and arterial blood and her fever subsided, the pain in both hip joints was unrelieved. Slight decalcification and cyst formation of both femoral heads were seen on $x$-ray and were considered consistent with aseptic necrosis. Because of the increasing leucopenia, chloramphenicol was withdrawn, and bacampicillin was given to prevent recurrence of bacillaemia. Although the patient became afebrile, the erythrocyte sedimentation rate remained high $(102 \mathrm{~mm}$ per hour). She was discharged on 29 September.

On her second admission to hospital a month $\stackrel{\mathbb{Q}}{\Omega}$ later she had a high fever (up to $40^{\circ} \mathrm{C}$ ) and increased pain in both hip joints. The white cell count was 


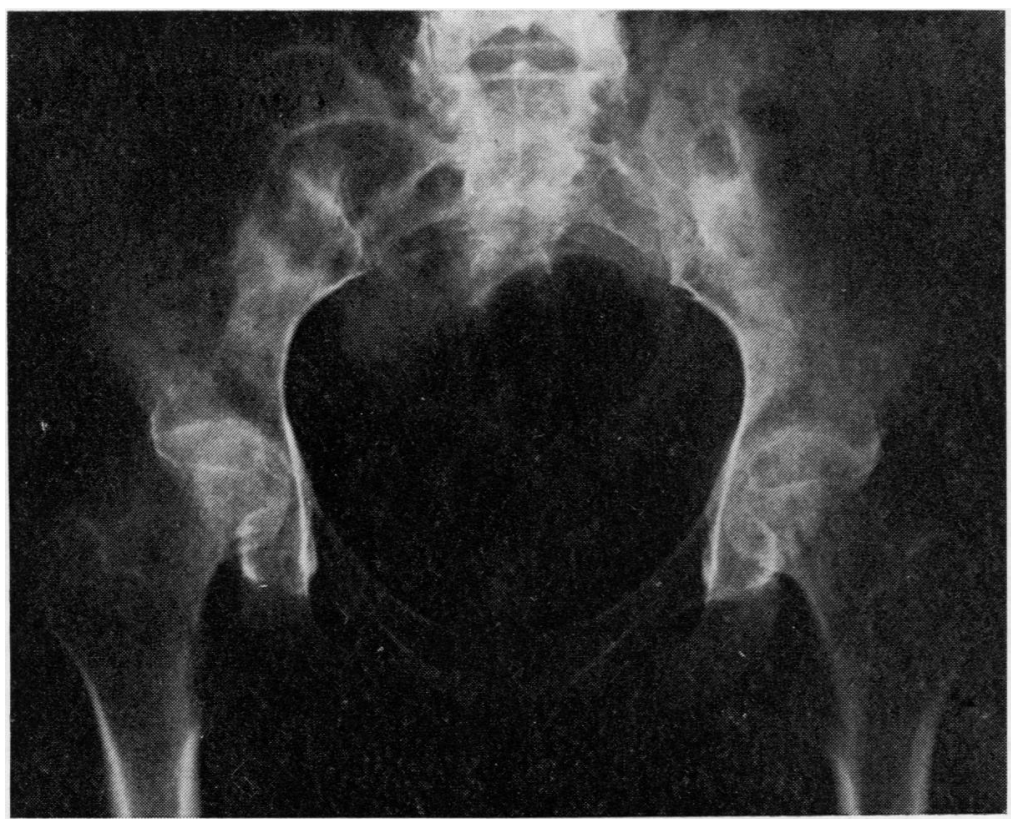

Fig. 1 X-ray film of both hips showing narrowing of the joint spaces and destruction of the femoral heads.

$12.5 \times 10^{9} / 1$, and the erythrocyte sedimentation rate was $127 \mathrm{~mm}$ per hour. An $x$-ray film of both hip joints (Fig. 1) showed narrowing of the joint spaces with irregular radiolucent areas in the femoral heads, and bone scanning with ${ }^{99} \mathrm{~m}$ Tc showed abnormal accumulation of radioactivity. Although arterial blood cultures were negative, aspirates of both hip joints yielded Salmonella typhimurium. Aminobenzyl penicillin (10 $\mathrm{g}$ per day), chloramphenicol ( 3 g per day), and gentamicin (120 mg per day) were successfully given, and her fever subsided. Cup arthroplasty of the right hip joint was performed. on 18 October and subsequently of the left hip joint on 19 December. The surgical wounds were irrigated with sulbenicillin and fosfomycin (1-cis-1, 2 epoxypropyl phosphonic acid). Cultures from the operative wounds grew salmonella, and immediately after the first operation fosfomycin was administered both systematically (6 $\mathrm{g}$ per day) and locally $(0.5 \mathrm{~g} /$ $500 \mathrm{ml}$ of glucose solution 4 times daily) during the drainage period. No organisms were detected in the washings of the surgical wounds on and after 24 January 1978, and the patient was discharged on 13 May with a normal erythrocyte sedimentation rate and normal ${ }^{99} \mathrm{~m}$ Tc bone scan.

\section{Comment}

The status of patients with systemic lupus erythematosus may be compromised by corticosteroid and immunosuppressive treatment and thus infections are not uncommon, ${ }^{3}$ although septic arthritis is rare. ${ }^{4}$ There is only one published report of coxitis caused by Salmonella typhimurium, and the diagnosis was confirmed at necropsy. ${ }^{2}$

In our patient it is thought that the infection was caused by ingestion of contaminated food which was brought to the hospital by a visitor, and that septic coxitis was a complication of gastro-intestinal and systemic salmonellosis. At first the arthralgia in the hip joints was thought to be due to aseptic necrosis of the femoral heads, which is a not infrequent complication of systemic lupus erythematosus. ${ }^{5}$ In retrospect we should have paid more attention to the persistent pain in both hips and to the abnormal erythrocyte sedimentation rate, which persisted even after eradication of salmonella from the arterial blood by systemic treatment with chloramphenicol and bacampicillin. Surgery, together with irrigation of the operative wounds with antibiotics, including fosfomycin, finally eradicated the organism from the affected joints.

The authors thank Dr Woodrow G. Wilson, who is a medical director of Nippon Welcome Co. Ltd, for his help in the preparation of this manuscript.

\section{References}

1 Quismorio F P, Dubois E L. Septic arthritis in systemic lupus erythematosus. $J$ Rheumatol $1975 ; 2$ : 73-82. 
314 Shiota, Miki, Kanayama, Kohno, Ohe, Takamatsu, Inoue

2 Castleman B, ed. Case records of the Massachusetts General Hospital. $N$ Engl J Med 1968; 278: 441-50.

3 Ginzler E, Diamond H, Kaplan D, Weiner M, Schlesinger $\mathbf{M}$, Seleznik $\mathbf{M}$. Computer analysis of factors influencing frequency of infection in systemic lupus erythematcsus. Arthritis Rheum 1978; 21 : 37-44.
4 Morris J L, Zizic T M, Stevens M B. Proteus polyarthritis complicating systemic lupus erythematosus. Johns Hopkins Med J 1973; 133: 262-9.

5 Abeles M, Urman J D, Rothfield N F. Aseptic necrosis of bone in systemic lupus erythematosus. Relationship to corticosteroid therapy. Arch Intern Med 1978; 138: 750-4.
क. $\Rightarrow$ 